Sedliacikova, M., Moresova, M., Alac, P., \& Drabek, J. (2021). How Do Behavioral Aspects Affect the Financial Decisions of Managers and the Competitiveness of Enterprises? Journal of Competitiveness, 13(2), 99-116. https://doi.org/10.7441/joc.2021.02.06

\title{
How Do Behavioral Aspects Affect the Financial Decisions of Managers and the Competitiveness of Enterprises?
}

\author{
- Mariana Sedliacikova, Maria Moresova, Patrik, Alac, Josef Drabek
}

\begin{abstract}
Decisions of financial managers can improve the competitiveness of the enterprise. Decisions are affected not only by knowledge and experience but also by emotional and cognitive deviations in behavior. Considering the role of competitiveness, this paper investigated whether an effect of behavioral factors on the financial decision-making of managers can be shown, and if so, to what degree. The aim of the paper is to propose a concept, the essence of which is to determine the key systematically-occurring errors in the financial decision-making process of managers rising from the effect of the human factor as a basis of prevention of incorrect financial decisions. The issue was mapped in the territory of the Visegrad Four (V4) by means of an empirical survey by the method of a questionnaire. By evaluating the research, the methodology of statistical hypotheses testing by measures of association was used (contingency coefficients - Cramer's contingency coefficient V and Pearson's contingency coefficient $\mathrm{C}$ ) and Pearson's chi-square test. The results of the research allow the formulation of conclusions that expand current knowledge in the field of research. The main results of the conducted research are that the key behavioral aspects (cognitive, psychological and emotional) that influence the financial decision-making process of business managers in the V4 countries are love, sadness and hate. A concept was created from the achieved results, the application of which in the enterprises of the V4 countries can help managers avoid making improper financial decisions which could have a negative impact on the financial health and competitiveness of an enterprise.
\end{abstract}

Keywords: financial decision-making, behavioral aspects, managers, competitiveness JEL Classification: D22, D23, D29, M12

Received: November, 2020

1st Revision: April, 2021

Accepted: April, 2021

\section{INTRODUCTION}

Heavy focus on behavioral finance began after Richard Thaler was awarded the Nobel Prize in the field of Economics. While behavioral finance is a newer field than economics, significant investigations in this field have been made during the last 50 years. The discipline represents a focus on problems of economic theory that result from the assumption of rationality. Publications 
on prospect theory and the replacement of behavioral economics with expected utility theory can be mentioned as the origin of behavioral finance. Prospect theory brought cognitive shortcuts, heuristics, and their substantial impact on the decision-making process. It contains three basic components as reference points: probability weighting, loss aversion and reduction of sensitivity. According to research by Statman (2008), in the field of behavioral finance, people critically underestimate probabilities and their objective value. Individuals arguably place extra emphasis on low probabilities but underweight high chances.

Fogel et al. (2006) has stated that financial decisions relate to how, when and where funds are to be acquired to meet investment needs. The study of financial decision-making emerged from financial information dealing with business performance. Financial decision-making sets the best course of action for the short-term and long-term period of business while taking into account current financial and economic reality. Recent theories such as those of Budhiraja et al. (2018) have indicated that, as the human does not always think rationally, neither do markets always perform efficiently. Particular psychological factors like greed and fear can influence the investment and financial decisions of managers.

Doing business means making decisions at all levels of an enterprise. Developed post-communist economies have had to transform from centrally planned into market economies, which also involved the application of new managerial and financial models and decision-making tools. This situation was also recorded in the so-called Visegrad countries (V4). Eurostat (2019) describes Visegrad countries as the region on the eastern border of the European Union. The location of this region makes it strategically important and creates opportunities for the member states (the Czech Republic, the Slovak Republic, Hungary and Poland) to utilize their partnership at the regional level as well as within the European Union. The principal force of V4 economic development remains their export orientation and foreign direct investment.

Nevertheless, in all V4 countries except for Poland domestic resources are lacking. A cheap but qualified labor force, tax exemptions and flexible labor rights rank among the most important competitive advantages within the V4 region. The economic strategy that makes the V4 countries attractive for business is simultaneously holding them hostage in the middle-income trap. These countries need additional resources for managing changes towards the knowledge-based economy based on innovation and higher investment in human capital.

This research investigated whether an effect of behavioral factors on the financial decisionmaking of managers is present, and, if so, to what degree. The goal of the study is to propose a concept, the essence of which is to determine the key systematically-occurring errors in the financial decision-making process of managers rising from the effects of the human factor as a basis of the prevention of unadvantageous finance decisions which could have a negative impact on the financial health and competitiveness of an enterprise.

\section{THEORETICAL BACKGROUND}

According to authors such as Corr et al. (2018), Thaler (2015), and Tversky \& Kahneman (1981), behavioral economics focuses on understanding human psychology and particularly why people deviate from rational actions when they make decisions. The researchers confirm that many 
people are inclined to choose an option that brings instant pleasure rather than the one which will beget long-term satisfaction at the expense of short-term gratification. Using behavioral economics, individuals and institutions can take advantage of this to manipulate individuals and groups into a specific course of action or purchase. Behavioral economics, which combines ideas from psychology and economics, provides valuable insights regarding the fact that individuals are not always behaving in their best interest. A knowledge mix from judgment and decisionmaking research is created in order to inform realistic assumptions about the thoughts, feelings and actions of individuals. A more cynical view is that behavioral economics is just repackaged psychology couched in terms more amenable to economics, but not "true" psychology, which is held in high regard. There is some truth to this claim.

As declared by Thaler (2015), Chataway (2020), Hossain et al. (2012), behavioral ideas are a key contributor to the arsenal of modern economics. They embrace the core principles of modern economics - optimization and equilibrium - and the wish to develop and refine these ideas to make them more empirically accurate. According to the researchers, people engage in negative behaviors, which means that economic models make numerous bad predictions. This can lead to serious consequences in decision-making. Virtually, no economists nor their models predicted the financial crisis in 2008, and what is worse, many thought that both the crash and the related implications were things that simply could not happen. It is evident that behavioral economics emerged against the spotlight of the traditional economic approach known as the rational choice model. The person is rational when he/she evaluates the costs and benefits accurately and calculates the best choices for himself. Regarding the connection of business and behavioral economics, it should be taken into account that every particular business needs customers to buy and use its products and services to generate revenue and to also improve enterprise competitiveness through an understanding of behavioral aspects. Nevertheless, many business practices fly in the face of the latest evidence on how and why people behave as they do. Or worse, a business frequently does not even try to change its behaviors, but merely its perceptions or attitudes, wrongly assuming that the behavior changes will follow. If there is one thing to learn from behavioral science, it is this: what people do is often not the same as what they say they do or intend to do. If a business does not employ this understanding of how people make decisions - frequently driven by subconscious or external factors they are not aware of - they are wasting the money of the business (and that of any shareholders).

As presented by Kaustia (2008), Chataway (2020) and Bollen et al. (2015), there is also a clear correlation between financial decision making and behavioral factors that should also be taken into account in the process of investment. To predict future stock prices and their changes based on publicly available information is not possible in an efficient market. Many early violations of this principle had no explicit link to behavior. So it was reported that small firms and "value firms" (those with a low price to earnings ratio) earned higher returns than other stocks with the same risk. These authors found in their work that some customers and investors were more likely to sell a stock that had increased value than one that had decreased. There is a field in finance in which a behavioral approach was least likely to succeed. The savings had to be the most promising. The standard life cycle model of savings abstracts from both bounded rationality and bounded willpower, but savings is both a complex cognitive problem and a difficult self-control 
problem. So, it is less surprising that a behavioral approach has been valuable here. Bollen et al. (2015) and Shotton (2018) confirmed that behavioral finance is focused on the influence of psychology on the behavior of managers, investors and financial analysts. It includes the subsequent effect on the markets, and it focuses on the fact that managers and investors are not always rational, have limits to their self-control, and are influenced by their own biases. Psychological and sociological factors have a great effect on the financial decision-making of managers. Sometimes, they are highly optimistic and self-confident during solving particular projects within teamwork. Their higher optimism can lead to wrong and irrational decisions. It is typical for behavioral finance that it enables us to learn from mistakes and experiences. Managers in various managerial levels can be influenced by their own optimism, and further, they can over-estimate particular future incidents. As it is a well-known fact, self-confidence can lead to mistakes and errors in decision-making, and highly self-confident managers tend to underestimate the risk of future results (Baker et al., 2010).

Close and important correlation between strategy making, financial management, decisionmaking and behavioral economics is also interpreted by Van Horne et al. (2008), Lowenstein et al. (2007), Armstrong and Huck (2010), who described financial management behavior as the determination, acquisition, allocation and utilization of financial resources with an overall goal in mind, while on the other hand, financial management behavior can be described as an area of financial decision-making, harmonizing individual incentives, ideas and enterprise goals. They indicate that effective financial management behavior should improve financial well-being positively, and failure to manage enterprise finance can lead to serious long-term negative social consequences. Enterprises typically operate within a highly complex and uncertain environment, and they need to consider not only their rivals' strategy. They often resort to decision-making shortcuts. Enterprises might rely on simple rules of making the strategies of well-performing rivals or changing strategies only when profit falls below some acceptable level, rather than on full calculation of complex optimal strategies.

An important implication of behavioral economics is that policy-makers and strategy-makers need to understand better the demand side of markets, in terms of how consumers actually behave and also how managers behave and react to that demand. Behavioral economics adopts more specific assumptions than traditional economics about consumer preferences, decisionmaking and choice. It takes account of a cornerstone of psychology that people rely on two cognitive systems: reflective system and automatic system (Gavriilidis et al., 2020).

Behavioral economics can provide useful insight into certain market situations and outcomes that are driven by consumer biases and bounded rationality and that can be understood or explained through behavioral economics. Phenomena such as search costs, switching costs and product differentiation have long been understood in the literature on industrial organizations and in competition policy. The added value of behavioral economics is that it can cast further light on what drives search costs and switching costs and on how product differentiation affects consumer behavior in each of the access, assess and act stages of the consumer decision-making process. Behavioral economics can then shed light on how enterprises might be able to exploit consumer biases but, at the same time, take into account and consider manager's behavioral aspects and attitudes to decision-making (Ruys, Aarts, 2010). 
According to Eurostat (2019), the V4 economies would be the 5th largest economy in Europe and 12th globally if it should be taken as a single-nation state. With its 64 million population, it would rank as the 22nd largest in the world and 4th in Europe. The EU 27 economic growth was $1.4 \%$ in 2019 and only $1.2 \%$ in the 19 -member eurozone. Central European economies rank among the fastest growing in the EU bloc. Despite some particular problems, these nations keep a pivotal role, at least for German exporters. According to the Centre for European Reforms, the V4 belong among Germany's most important trade partner, ahead of the United States and China, due to their integration process in EU-wide supply chains.

\section{RESEARCH OBJECTIVES, METHODOLOGY AND DATA}

The goal of the study is to propose a concept, the essence of which is to determine the key, systematically occurring errors in the financial decision-making process of managers, rising from the effect of the human factor, as a basis of prevention of incorrect finance decisions, which could have a negative impact on the financial health and competitiveness of an enterprise. In the first stage of the study, it was necessary to elaborate on literature research through the analysis of secondary sources. Based on the available information from domestic and foreign authors, the goal, hypotheses and methodology of the primary research of the study were determined.

Primary data were obtained through a questionnaire survey. When considering that each managerial decision making affects the financial situation and also competitiveness of a company, the research was aimed to identify key emotional, psychological and cognitive factors that affect the financial decision-making process at managers in the V4 countries. The research was conducted in 2019 .

Inner consistency of a questionnaire was evaluated by the Cronbach alpha coefficient (Cronbach, 1951):

$\alpha=\frac{\mathrm{k}}{\mathrm{k}-1} \times\left(1-\frac{\sum_{\mathrm{i}=1}^{\mathrm{k}} \mathrm{s}_{\mathrm{i}}^{2}}{\mathrm{~s}^{2}}\right)$

where: $\mathrm{k}-$ is the number of test items; - is the sum of the item variance; s 2 - is the variance of the total score. The level of Cronbach alpha is 0.75 , which means from the point of view of consistency, our questionnaire could be accepted (Cronbach, 1951).

The questionnaire was distributed among enterprises operating in the V4 countries, i.e., Slovakia, Poland, Hungary and the Czech Republic. Our questionnaire was translated and send to relevant countries in the national language. According to the European Commission (2018a; 2018b; 2018c; 2018d), there were 3,721,708 enterprises operating in the V4 in 2018 (434,619 enterprises in the Slovak Republic, 559,336 in Hungary, 1,031,762 in the Czech Republic and 1,695,991 in Poland). These enterprises of the V4 countries belong to the basic file of a questionnaire survey. The selected file of enterprises (Bureau Van Dijk, 2018) was chosen on the basis of random stratified choice (Hong, 2017). The questionnaire was sent to enterprises with the position of a financial manager. This step can lead to the situation that a manager was meant as an enterprise because of the assumption that a financial manager makes decisions that affect the enterprise's financial health 
and its competitiveness. Factors like age and gender of managers were not considered because there is very personal and intimate information which could decline the questionnaire efficiency. At the same time and for the same reason, there was not investigated time of managers' experience. A total of 18,000 respondents were contacted. The return was $2.24 \%$ (403 questionnaires).

The questionnaire was divided into two parts. The first part of the questionnaire contained classification questions aimed at differentiating respondents according to the size of the enterprise (micro, small, medium and large), type of enterprise (manufacturing and non-manufacturing sector), the V4 countries where the enterprise is located (Slovakia, Hungary, the Czech Republic, Poland), time of operating on the market (less than 1 year, less than 5 years, less than 15 years and more than 15 years) and the internal interest group in the company (employee, shareholder, manager). The second part of the questionnaire contained questions aimed at expressing the consent or disagreement of respondents with the statements in the field of cognitive, psychological and emotional factors. Respondents expressed their opinion using the Likert scale (-2 - very negative, -1 - negative, 0 - I don't know, 1 - positive, 2 - very positive) for each cognitive, psychological, and emotional factor.

In order to generalize the results, the minimum number of respondents was calculated according to the methodology for determining the minimum sample size (Hong, 2017):

$$
n \geq \frac{z^{2} \times \mathrm{p} \times(1-p)}{c^{2}} \rightarrow n \geq \frac{1.96^{2} \times 0.5 \times(1-0.5)}{0.05^{2}} \rightarrow n \geq 384
$$

$\mathrm{n}-\mathrm{a}$ minimum number of respondents required; $\mathrm{z}$ - level of reliability (at the reliability of $\quad 95.0 \%$; $\mathrm{z}=1.96$ ); $\mathrm{p}$ - the proportion of the character (for unknown values it is substituted for $\mathrm{p} 0.5$ ); $\mathrm{c}-$ acceptable error value, set at the level of $5 \%$.

It results that the sample size shall consist of at least a sample of 384 respondents, i.e., managers of enterprises.

To meet the objective of the paper, it was necessary to exclude respondents who were owners or employees in the enterprise out of the total number of 403 obtained answers. Out of the total number, 384 respondents $(95.3 \%$ ) were managers and only $4.7 \%$ of respondents were employees or owners of the enterprises. After excluding responses from employees and owners, it can be stated that the results of the survey can be generalized to the whole basic set - the survey meets the condition of a minimum sample size.

The following hypotheses were defined from the literature review:

H1: It is assumed that managers do not control their decision-making behavior and are not able to exercise self-control in thinking.

H2: It is assumed that human behavior is important in evaluating economic decisions.

H3: It is assumed that there is a statistical difference between emotional factors like love, hate and sadness that affected the financial decision-making of managers, which has an impact on the financial health and competitiveness of an enterprise.

H4. It is assumed that there is a statistically important difference between the rational decision process of managers according to emotional factors. 
The statistical software Statistica 10 was used to evaluate the research results. The hypotheses were tested with a significance level of 5\%, i.e., $\alpha=0.05$. Graphical and descriptive methods were used to evaluate hypotheses $\mathrm{H} 1$ and $\mathrm{H} 2$. Hypotheses $\mathrm{H} 3$ and $\mathrm{H} 4$ were evaluated by measures of association - contingency coefficients (Cramer's contingency coefficient V and Pearson's contingency coefficient C) and Pearson's chi-square test. Nonparametric chi-square statistic can be used because of the fact that there are used categorical data under ordinal interval which express the opinion of subjects on the particular questionnaire questions. Pearson's coefficient of contingency $\mathrm{C}$ helped for the following of the strength of dependence between the qualitative factors. Cramer's V Coefficient was useful for comparing multiple chi-square test statistics.

\section{RESULTS AND DISCUSSION}

The next part of the study presents the results of the questionnaire survey and verification of hypotheses aimed at identifying key behavioral aspects (emotional, psychological and cognitive) that affect the financial decision-making process at managers in enterprises in the V4 countries. It is necessary to take into account that each particular decision affects the financial health and competitiveness of an enterprise.

In the main part of the questionnaire, the first statement was focused on the verification of whether managers made several important decisions during their managerial practice. In total, up to $99.7 \%$ of managers stated that they had to make crucial decisions during the executing of their profession. Only $0.3 \%$ of managers could not express themselves unequivocally. As the authors like Stojanovic et al. (2020), Ziolkowska (2020), Tabesh et al. (2020) and Fagundes et al. (2021) state, managers at all levels of management must continuously make decisions that affect the operation and competitiveness of the company. Existence of an enterprise also depends on their fast and targeted decisions.

In the decision-making process, the managerial problem can be solved through analytical and quantitative methods. These include various expert methods (brainstorming, discussion), exact methods (mathematical statistics, analysis), decision trees. Managers use some of these methods to make decisions. However, they sometimes prefer their experience and intuition.

The second statement sounds as follows: "In situations when I have enough time to make a decision, I decide based on quantitative and analytical methods rather than on my intuition." Most of the managers $(58.9 \%)$ perceive this statement very positively, if they have enough time to make decisions, they rather use quantitative or analytical decision-making methods. At the same time, another $22 \%$ of managers perceive this statement positively. On the contrary, $15.1 \%$ of managers do not agree with this statement. Other managers (4\%) could not express themselves unambiguously. It is possible to take measures only through a complex assessment of the decision and its effects that will solve the current problem but will not jeopardize the future of the enterprise and its competitiveness. At the same time, it should be kept in mind that there are not always ideal conditions where there is time for analysis, and managers must make urgent decisions based on their intuition and experience.

The quality of managerial decisions affects the results achieved in the enterprise and its competitiveness. The decision-making process of managers is influenced by certain factors. 
The authors found out in the third statement whether managers, in case of adequately structured problems they had already had solved several times, omit one of the steps of the decision-making process (e.g., search, formulation, analysis of alternatives). Up to $67.9 \%$ of managers reacted very positively to the statement, and another $28.6 \%$ reacted positively. Only $2.7 \%$ of respondents perceived this statement negatively, and $0.8 \%$ could not express themselves unambiguously.

The hypothesis $\mathrm{H} 1$ relates to the seventh statement: It is assumed that managers do not control their decision-making behavior and are not able to exercise self-control in thinking. As many as $87 \%$ of managers (Table 1) are able to direct their behavior and actions, so that self-control of thinking occurs. The statement was confirmed by the positive answers of the managers. Therefore, it is necessary to reject hypothesis H1. As Stojanovic et al. (2020), Habanik et al. (2020), Sajid et al. (2019) and Asebedo et al. (2019) state, irrational managerial behavior is behavior that deviates from rational expectations, and the maximization of utility value is expected.

The validity of the hypothesis $\mathrm{H} 2$ was verified by the eighth statement. The behavior of a man reflects his abilities. When making decisions of any nature, it is essential to perceive reality and rely on the achieved results. Nearly $79 \%$ of managers (Table 1) expressed positively about the statement. The results confirm the validity of the hypothesis $\mathrm{H} 2$ that human behavior is important at evaluating economic decisions. Thus, managers are aware of their behavior and perceive the changes that financial decisions bring.

To identify the behavioral factors that are the main cause of the change in acting and behavior of the subjects, the ninth statement was included in the questionnaire. As Table 1 shows, more than $58 \%$ of managers perceive the statement very positively and another $17.2 \%$ positively. It follows that love, fear and hatred are the reason for most managers to change their acting and behavior. These results support the validity of the hypothesis H3, where it is supposed that there is a statistically important difference between the impact of emotional factors like love, hate and sadness on the financial decision-making process of managers, which has an impact on the financial health and competitiveness of an enterprise. However, for absolute confirmation of $\mathrm{H} 3$, it is necessary to perform a mathematical-statistical analysis.

The following Table 1 describes the answers of managers to particular statements.

Tab. 1 - Responses to the statements $4-9$. Source: own research

\begin{tabular}{|l|l|l|l|l|l|l|}
\hline \multicolumn{2}{|l|}{ Statements } & \multicolumn{2}{l|}{ Answers } \\
\cline { 3 - 7 } & $\begin{array}{l}\text { very } \\
\text { negative }\end{array}$ & negative & $\begin{array}{l}\text { don't } \\
\text { know }\end{array}$ & positive & $\begin{array}{l}\text { very } \\
\text { positive }\end{array}$ \\
\hline fourth & $\begin{array}{l}\text { using intuition in the } \\
\text { decision-making process }\end{array}$ & $0.5 \%$ & $8.5 \%$ & $0.8 \%$ & $23.1 \%$ & $67.1 \%$ \\
\hline fifth & $\begin{array}{l}\text { application of intuition in } \\
\text { complicated situations }\end{array}$ & $0.5 \%$ & $9.0 \%$ & $2.1 \%$ & $33.7 \%$ & $54.7 \%$ \\
\hline
\end{tabular}




\begin{tabular}{|l|l|l|l|l|l|l|}
\hline sixth & $\begin{array}{l}\text { preference of own intuition } \\
\text { leads to profit-increasing } \\
\text { decisions }\end{array}$ & $0.3 \%$ & $5.5 \%$ & $6.9 \%$ & $38.2 \%$ & $49.1 \%$ \\
\hline seventh & self-control in thinking & $0 \%$ & $0.5 \%$ & $1.3 \%$ & $11.2 \%$ & $87.0 \%$ \\
\hline eighth & $\begin{array}{l}\text { behavior and its impact on } \\
\text { economic decisions }\end{array}$ & $0 \%$ & $0.2 \%$ & $0 \%$ & $21.0 \%$ & $78.8 \%$ \\
\hline ninth & $\begin{array}{l}\text { attitude of managers to } \\
\text { emotions such as fear, love } \\
\text { and hate }\end{array}$ & $4.5 \%$ & $13.3 \%$ & $6.9 \%$ & $17.2 \%$ & $58.1 \%$ \\
\hline
\end{tabular}

In the next part of the study, through mathematical-statistical analysis, the authors point out the key behavioral aspects (emotional, psychological and cognitive) that affect the financial decisionmaking process of managers in the enterprises in the V4 countries. The analysis is necessary for the absolute confirmation of the hypothesis $\mathrm{H} 3$, but also to verify the validity of the hypothesis $\mathrm{H} 4$, where it is supposed that there is a statistically important difference between the impact of rational behavior of managers related to emotional factors.

Based on the statistical evaluation of the influence of love on the financial decision-making process of managers in the V4 countries, it was possible to confirm the interdependence between the individual variables (Table 2$)$. The $\mathrm{p}(<0.05)$ confirms these results, i.e., the null hypothesis was rejected in favor of the alternative hypothesis, confirming the existence of interdependence between managers and love as a behavioral (emotional) factor. Cramer's contingency coefficient (Table 2) confirmed a weak dependence between the observed traits.

Tab. 2 - Dependence between the job position and love. Source: own research

\begin{tabular}{|l|l|l|l|}
\hline \multirow{2}{*}{ Statistics } & \multicolumn{3}{|l|}{ Statistics: managers and love } \\
\cline { 2 - 4 } & Chi-square & Degrees of freedom & p-value \\
\hline Pearson's Chi-square test & 18.0118 & $\mathrm{df}=2$ & 0.00012 \\
\hline M-V Chi-square test & 16.0909 & $\mathrm{df}=2$ & 0.00032 \\
\hline$\Phi$ & 0.2114 & & \\
\hline Contingency coefficient & 0.2068 & & \\
\hline Cramer's V & 0.2114 & & \\
\hline
\end{tabular}

Using a mathematical-statistical test, the dependence between the job position and the influence of hate on the financial decision-making process was determined. At the level of significance of $5 \%(\alpha=0.05)$, it is possible to reject the null hypothesis even with this factor, where the basis was the observance of the condition of good approximation (Table 3). The results confirmed that hate influences managers' decisions and changes their behavior. 
Tab. 3 - Dependence between the job position and hate. Source: own research

\begin{tabular}{|l|l|l|l|}
\hline Statistics & \multicolumn{3}{|l|}{ Statistics: managers and hate } \\
\hline & Chi-square & Degrees of freedom & p-value \\
\hline Pearson's Chi-square test & 7.153 & $\mathrm{df}=2$ & 0.02797 \\
\hline M-V Chi-square test & 10.105 & $\mathrm{df}=2$ & 0.00639 \\
\hline$\Phi$ & 0.1332 & & \\
\hline Contingency coefficient & 0.1321 & & \\
\hline Cramer's V & 0.1332 & & \\
\hline
\end{tabular}

Based on statistical observation, the p-level was lower than the selected level of significance $(p<0.05)$, which confirms the validity of the alternative hypothesis, i.e., there is a dependence between sadness as an emotional factor and managers' financial decision-making process (Table 4). Cramer's contingency coefficient $V$ confirmed a weak dependence between the observed traits.

Tab. 4 - Dependence between the job position and sadness. Source: own research

\begin{tabular}{|l|l|l|l|}
\hline Statistics & \multicolumn{3}{|l|}{ Statistics: managers and sadness } \\
\hline & Chi-square & Degrees of freedom & p-value \\
\hline Pearson's Chi-square test & 15.886 & $\mathrm{df}=2$ & 0.00036 \\
\hline M-V Chi-square test & 14.860 & $\mathrm{df}=2$ & 0.00059 \\
\hline$\Phi$ & 0.199 & & \\
\hline Contingency coefficient & 0.195 & & \\
\hline Cramer's V & 0.199 & & \\
\hline
\end{tabular}

The task of the above-mentioned mathematical-statistical analysis was to identify specific behavioral factors that are the source of behavioral change of managers and can lead to incorrect decisions. The results of the analysis clearly confirmed the validity of the hypothesis H3, i.e., that there is a statistically important difference between the impact of emotional factors like love, hate and sadness on the financial decision-making process which affects the financial health and competitiveness of enterprises. By means of the previous hypothesis (H3), it was possible to determine three key behavioral factors. Statistical dependence was studied between two variables. With the calculation of Pearson's chi-square test, the Cramer's contingency coefficient $\mathrm{V}$ and Pearson's contingency coefficient $\mathrm{C}$, the authors found that $\mathrm{H} 4$ was confirmed. The key behavioral factors that influence the managers' financial decision-making process are emotional factors: love, hate and sadness.

Frydman et al. (2016) agree that behavioral factors, which prevent the right financial decision, include psychological, emotional and cognitive factors. Authors Kapoor et al. (2016) and Valaskova et al. (2019) reason the fact that the subject is not able to identify and influence his internal thinking and defer it from objectivity. Financial decision-making is the basis of the correct functioning of an enterprise and depends on the acting and behaving of the subject of the decision-making. In this case, the subject of decision-making is the manager who is responsible for the operation of the enterprise and leads the others to achieve the goals of the enterprise and strengthen the competitiveness of the enterprise. Human feelings affect the decision and 
are an inseparable part of life. Managers are often also responsible for their subordinates, with whom they work or participate in the decision-making of the company and enhancing its competitiveness. Despite the support tools that can often be used to make decisions, managers in difficult situations must rely on their previous experience, skills and intuition. The point lies mainly in being aware of the responsibility for decisions, which is noticed in the study of Lau et al. (2017), who claims that human feelings such as love, hate and sadness influence the proper way of making decisions. Similarly, the results of the study by Shu et al. (2020) confirm the fact that hate and sadness impact the rational behavior and decision-making of managers. In particular, sadness and hate make managers less patient and more sensitive to negative experiences. At the same time, resistance to risk-taking can appear. Authors Bilan et al. (2020), Sun et al. (2020), Brown et al. (2020), Remenova et al. (2019), Valaskova et al. (2019), Frydman et al. (2016), Kapoor et al. (2016), agree that it is necessary to accept individual aspects of behavior that affect the decision-making process of managers. To ensure effectively the existence of the enterprise and its competitiveness, it is necessary to understand the importance of the impact of individual factors on their decision-making process in the enterprise and thus timely prevent mistakes that can cause the use of intuitive decision-making instead of management with rationality and professionalism of managers.

As Lu et al. (2020) and Mohamad Radzi et al. (2017) emphasize that it is important that all enterprises communicate actively and monitor their business environment because it directly impacts the development, competitiveness or the very existence of the enterprise. The enterprise alone cannot fundamentally change the business environment at will. It is important to identify its key determinants and accordingly adapt its strategy. At the same time, to ensure competitiveness, an enterprise requires managers who will implement decisions that are beneficial for the competitiveness and long-term existence of the enterprise. Managers as well as other human beings make mistakes due to their emotions. Remenova et al. (2019), Habanik et al. (2020) revealed similar results in their research. As Ramani (2019) and Frydman et al. (2016) indicate, the most frequent errors of managers at the financial decision-making process that directly affect the competitiveness of the enterprise include mainly: insufficient identification of the problem, formulation of solution alternatives with reserves, adoption of the wrong alternative solution, tendency to risk, wrong assessment of alternatives, implementation of wrong solution alternative and insufficient solution of the problem.

All this can happen if the manager is influenced by external or internal (own factors). By creating a concept, we can eliminate wrong decisions, and only by the fact that the manager has information about how behavioral factors change his behavior, will he try to think more rationally. Thanks to three key behavioral factors identified by the statistical testing, it is possible to design a concept of systematically occurring errors in the decision-making of managers (Figure 1) and take the following measures. On the basis of a given concept presented in Figure 1, financial managers could not make irrational decisions that can lead to the support of enterprise competitiveness, financial health and market value. 


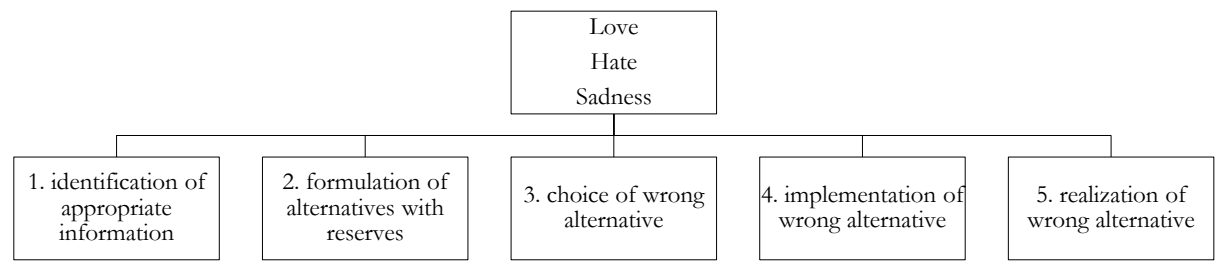

Fig. 1 - Concept of actuation of three key behavioral factors. Source: own research

The authors developed this basic concept and created a concept (Figure 2), which represents a comprehensive description of the decision-making process applying three key behavioral factors.

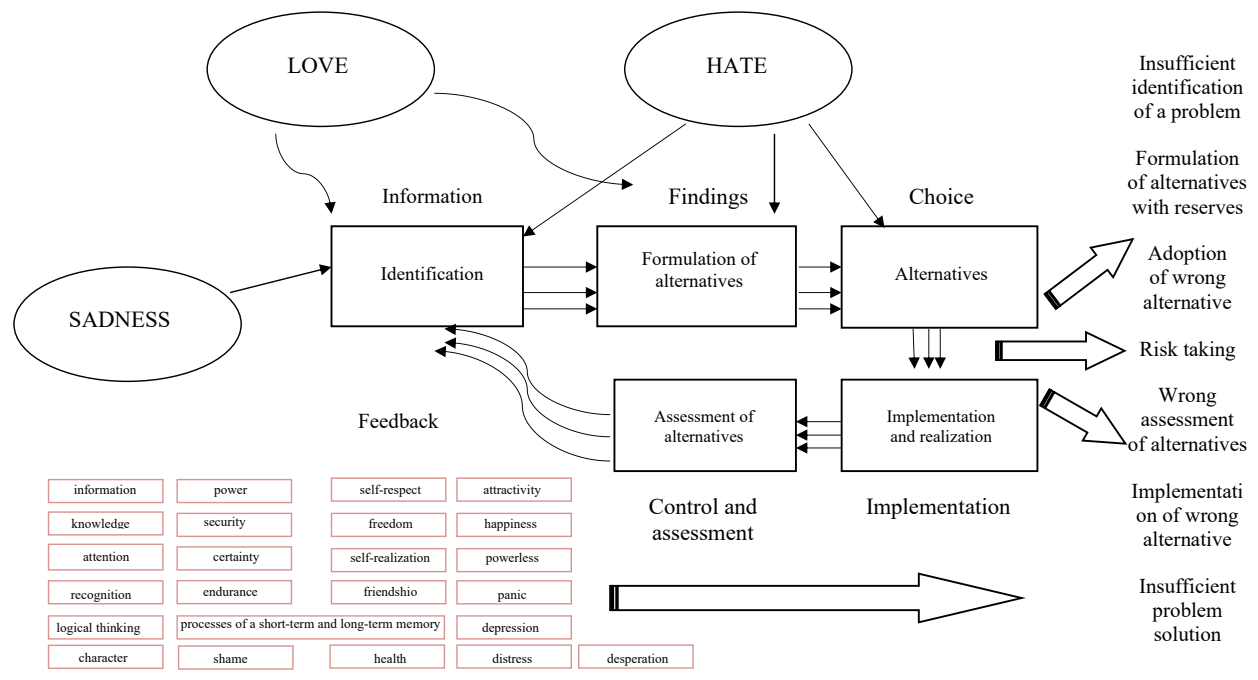

Fig. 2 - The concept of the decision-making process applying three key behavioral factors. Source: own research

The authors of this research emphasize that this concept is a new approach to the correct understanding of managers' behavior and the factors that influence their business decisions. Input data were collected through doing empirical research and its evaluation done by selected measures of association. The results point to the fact that love, hate and sadness are the main behavioral factors that influence the rational decision-making of managers. We remind that all decisions made by managers in the enterprise affect its competitiveness and sustainability. For these reasons, it is necessary to eliminate errors in the financial decision-making process, which are (according to the results of the study) caused mainly by three behavioral factors: love, hate and sadness. The author Ramani (2019) achieved similar results in his research and found out that the more complex the decision-making process is, the more emotions managers put into decision-making and act irrationally. Similarly, the author Chaudhary (2013) concluded that emotional and cognitive factors influence the rational decisions of managers in enterprises.

Love is a factor that is perceived towards colleagues in working life and towards the family 
in personal life. Sympathy towards colleagues plays an important role in working life. On the contrary, hate is also associated with love. The reluctance to listen, help or advise someone can be a source of error in the first phase of decision-making in the form of a lack of appropriate information. A manager who does not seek consultation or advice from anyone should realize that when choosing the right information he will come across data that will be insufficient and will not be related to the specific problem-solving. When the first problem or the first error in a phase occurs, it is carried through the whole process. If the right information is not accessible, the possible solution alternatives will not contribute to problem-solving in the decision-making process. The choice of alternatives is also conditioned by these factors. Sadness is a factor that prevents rational thinking and this feeling can absorb an entire thought process. It is possible to assume that if an error occurs in the first phase, the feedback will show that the choice of the solution alternative was not correct. Valaskova et al. (2019), Frydmane et al. (2016), and Kapoor et al. (2016) emphasize that managers should always keep in mind the existence of these behavioral factors when preparing decisions. The manager must attempt to rid himself of all thoughts that hinder logical thinking, i.e. hate towards others. The manager must listen carefully and communicate with colleagues with love and forget about sadness. Managers can prevent errors in the decision-making process, e.g.: by determining the value system, monitoring the nature and significance of the decision-making problem, accepting the decisions of others, listening to the opinions of colleagues, making enough time for work and decisions, not dragging private matters into working life, remaining optimistic and self-critical, not attempting to solve all problems alone, realizing the need for communication with employees, remaining ambitious, and eliminating the influence of all negative behavioral factors. By eliminating the negative behavioral factors in the decision-making process, managers will be able to implement effective decisions that are expected to lead the company to success, competitiveness and long-term sustainability.

In taking into account that each enterprise maintains a number of specific internal features, it becomes necessary to adjust the proposed model according to particular conditions. All financial managers agreed with the testing of the proposed model, and all three enterprises operate in the Slovak Republic. After the coaching dealing with three basic behavioral factors, the authors can state that the financial managers confirmed that the proposed model focused on underestimated decision factors. These managers confirmed that they could actually better separate their feelings from decision-making, which increased the financial health and competitiveness of these enterprises.

\section{CONCLUSION}

The business environment continuously influences the activities in an enterprise and the decisions of its managers. It is essential that to ensure the stability, competitiveness and long-term sustainability of the enterprise, managers should make effective decisions, especially in the field of finance. Nevertheless, the decisions of managers are affected by psychological and sociological factors which are explained by behavioral finance. Managers or other executive employees are individuals who can be influenced by their own emotions, which leads to and overestimating or underestimating certain events that could lead to errors in the decision-making process. 
This paper investigated whether the effect of behavioral factors on the financial decision-making of managers is important, and if so, to what degree. The goal of the study was to propose a concept, the essence of which is to determine the key systematically-occurring errors in the financial decision-making process of managers rising from the effects of the human factor as a basis for the prevention of incorrect finance decisions which could have a negative impact on the financial health and competitiveness of an enterprise.

The results of the research showed that every manager must make decisions in terms of whether they can predict their behavior and are able to influence it. The authors verified that the intuition of managers affects the decision-making process, which was confirmed by more than $61 \%$ of respondents. However, if they have enough time to make decisions and are unsure of the potential result, they rely on quantitative and analytical methods. But the use of their intuition is not refuted. The first hypothesis, which assumed that that managers do not control their decisionmaking behavior and are not able to exercise self-control in thinking, was not confirmed. Up to $87 \%$ of managers are able to control their behavior and actions, thus self-control in thinking was verified. More than half of managers stated that decisions based on their intuition brought results that maximized profits for the enterprise. At the same time, the respondents agree that in the case of clear and well-structured problems, they may omit some steps in the decision-making process. In this case, it is possible to express that managers rely on their intuition. The second hypothesis assumed that human behavior was important in evaluating economic decisions. It was possible to confirm this hypothesis based on the answers of managers $(79 \%)$ who agreed with the statement.

Subsequently, through mathematical-statistical analysis, it was possible to identify specific behavioral factors that are a source of change in the behavior of managers and could lead to incorrect decisions. The results confirmed the influence of love on the financial decision-making process of managers in the enterprises in the V4 countries ( $p<0.05)$. Similarly, at a level of significance of $5 \%$ it was possible to confirm the impact of hate on manager decisions, which would cause a change in their behavior. The third key emotion that affects the decision-making process was identified based on a statistical observation of the p-value, which was lower than the selected level of significance $(\mathrm{p}<0.05)$. The results showed this factor was sadness. The performed analyses confirmed the validity of the hypothesis $\mathrm{H} 3$, that there is a statistically important difference between an impact of emotional factors like love, hate and sadness on the financial decision-making process which affects the financial health and competitiveness of enterprises. Through the calculation of Pearson's chi-square test, Cramer's contingency coefficient V and Pearson's contingency coefficient C, the authors confirmed the hypothesis H4. The key behavioral factors that influence managerial financial decision-making process are emotional factors: love, hate and sadness.

Based on the achieved results, the concept of the actuation of key behavioral factors was proposed. This was subsequently developed into the concept of the decision-making process at the application of three key behavioral factors, the essence of which is to determine the key systematicallyoccurring errors in the financial decision-making process of managers. The elimination of negative behavioral factors in the financial decision-making process is a prerequisite for more effective management decisions that have the potential to foster performance growth, competitiveness as well as the long-term prosperity and sustainability of enterprises. 
This research had some principal limitations which should be mentioned. One of these was the lack of including demographic factors like age and gender, which were not the object of this research. The authors have realized that these factors could be a part of future research which could bring relevant results related to these present research results. Moreover, the time of managers' experience was not investigated, which could have affected the results due to the assumption that managers with long-term experience can better manage decision-making in relation to behavioral factors. To obtain general results, the level of minimum required number of respondents was respected. Still, the number of respondents can be mentioned as a limitation of our research on the level of the basic file. The questionnaire was distributed among enterprises operating in the V4 countries in each national language. Therefore, a few mistakes in the translation of particular questions could have occurred. The proposed model was verified through the practice of three Slovak enterprises. This could also be mentioned as a research limitation because the model was not verified and validated among the other V4 countries. Despite these limitations, however, the results allow us to formulate relevant conclusions that expand current knowledge in the field of the presented research.

Acknowledgment: The authors are grateful for the support of the Slovak Research and Development Agency grants number APVV-18-0520, APVV-18-0378, APVV-17-0456, APVV17-0583 and APVV-20-0004 as well as funding from the project VEGA 1/0161/21.

\section{References}

1. Armstrong, M., \& Huck, S. (2010). Behavioural economics as applied to firms: A primer. Competition Policy International, 6 (1), 3-45.

2. Asebedo, S. D., Seay, M. C., Archuleta, K., \& Brase, G. (2019). The psychological predictors of older preretirees' financial self-efficacy. Journal of Behavioral Finance, 20 (2), 127-138. https://doi. org/10.1080/15427560.2018.1492580

3. Baker, H. K., \& Nofsinger, J. R. (2010). Behavioral Finance: Investors, Corporations and Markets. Hoboken, New Jersey: John Wiley and Sons.

4. Bilan, Y., Mishchuk, H., Roshchyk, I., \& Kmecova, I. (2020). An analysis of intellectual potential and its impact on the social and economic development of European countries. Journal of Competitiveness, 12 (1), 22-38. https://doi.org/10.7441/joc.2020.01.02

5. Bollen, K., Cacioppo, J., Kaplan, R., Krosnic, J. A., \& Olds, J. L. (2015). Social, Behavioral and Economic Sciences Perspectives on Robust and Reliable Science. Retrieved July 14, 2020 from https://www.nsf.gov/sbe/AC

6. Brown, K. C., Tiu, C. \& Yoeli, U. (2020). The decision to concentrate: Active management, manager skill, and portfolio size. Journal of Portfolio Management, 46 (5), 41-62. https://doi. org/10.3905/jpm.2020.1.136

7. Budhiraja, K., Raman, T. V., \& Bhardwaj, G. N. (2018). Impact of Behavioral Finance in Investment Decision Making. International Journal of Civil Engineering and Technology, 9 (6), $1151-1157$.

8. Bureau Van D. (2018). Orbis - growing database of companies and other entities. Retrieved February 14, 2018 from https://www.bvdinfo.com/orbis 
9. Chataway, R. (2020). The Behaviour Business: How to apply behavioural science for business success. London: Harriman House.

10. Chaudhary, A. K. (2013). Impact of behavioral finance in investment decisions and strategies - a fresh approach. International Journal of Management Research and Business Strategy, 2 (2), 85-92. http://iaeme.com/Home/issue/IJCIET?Volume=9\&Issue $=6$

11. Corr, P. A. \& Plagnol, A. (2018). Behavioral Economics: The Basics. London: Routledge.

12. Cronbach, L. J. (1951). Coefficient alpha and the internal structure of tests. Psychometrika, 16, 297-334. https://doi.org/10.1007/BF02310555

13. European Commission. (2018a). SBA Fact Sheet Slovakia. Brussels: European Communities. Retrieved July 6, 2018 from https://ec.europa.eu/docsroom/slovakia

14. European Commission. (2018b). SBA Fact Sheet Hungary. Brussels: European Communities. Retrieved July 6, 2018 from https://ec.europa.eu/docsroom/hungary

15. European Commission. (2018c). SBA Fact Sheet Czech Republic. Brussels: European Communities. Retrieved July 6, 2018 from https://ec.europa.eu/docsroom/czech_republic

16. European Commission. (2018d). SBA Fact Sheet Poland. Brussels: European Communities. Retrieved July 6, 2018 from https://ec.europa.eu/docsroom/poland

17. Eurostat. (2019). Fact Sheet Visegrad countries. Retrieved February 14, 2019 from https:// ec.europa.eu/eurostat/

18. Fagundes, E., Schnorrenberger, D., Gasparetto, V., \& Lunkes, R. J. (2021). Manager Risk tolerance: Analysis in decision-making in personal and organizational fields. Revista Evidenciacao Contabil \& Financas, 9 (1), 22-43. https://doi.org/10.22478/ufpb.2318$1001.2021 \mathrm{v} 9 \mathrm{n} 1.49966$

19. Fogel, S., \& Berry, T. (2006). The disposition effect and individual investor decision: The roles of regret and counterfactual alternatives. Journal of Behavioral Finance, 7 (2), 107-116. DOI:10.1207/s15427579jpfm0702_5

20. Frydman, C., \& Camerer, C. (2016). The psychology and neuroscience of financial decision making. Trends in Cognitive Science, 20 (9), 1-15. https://doi.org/10.1016/j.tics.2016.07.003

21. Gavriilidis, K., Kallinterakis, V., \& Öztürkkal, B. (2020). Does mood affect institutional herding? Journal of Behavioral and Experimental Finance, 26, 100290. https://doi.org/10.1016/j. jbef.2020.100290

22. Habanik, J., Martosova, E., \& Letkova, N. (2020). The impact of managerial decision-making on employee motivation in manufacturing companies. Journal of Competitiveness, 12 (2), 38-50. https://doi. org/10.7441/joc.2020.02.03

23. Hong, Y. (2017). Probability and Statistics for Economists. Singapore: World Scientific Publishing Company. https://doi.org/10.1142/10675

24. Hossain, T., \& List, J. A. (2012) The behavioralist visits the factory: Increasing productivity using simple framing manipulations. Management Science, 58 (12), 2151-2167. https://doi. $\operatorname{org} / 10.3386 /$ w15623 
25. Kapoor, S., \& Prosad, J. M. (2016). Behavioural finance: A review. Procedia Computer Science, 122, 50-54. https://doi.org/10.1016/j.procs.2017.11.340

26. Kaustia, M., Alho, E., \& Puttonen, V. (2008). How much does expertise reduce behavioral biases? The chase of anchoring effects in stock return estimates. Financial Management, 37, 391-412. https://doi.org/10.1111/j.1755-053X.2008.00018.x

27. Loewenstein, G., \& Haisley, E. (2007). The Economist as Therapist: Methodological Ramifications of "Light" Paternalism. The Foundations of Positive and Normative Economics: A Hand Book. Oxford: Oxford University Press.

28. Lu, Z., Gozgor, G., Huang, M., \& Lau, M. Ch. K. (2020). The impact of geopolitical risks on financial development: evidence from emerging markets. Journal of Competitiveness, 12 (1), 93-107. https://doi. org/10.7441/joc.2020.01.06

29. Mohamand Radzil, K., Mohd Nor, M. N., \& Mohezar Ali, S. (2017). The impact of internal factors on small business success: a case of small enterprises under the FELDA scheme. Asian Academy of Management Journal, 22 (1), 27-55. https://doi.org/10.21315/aamj2017.22.1.2

30. Ramani, P. (2019). Emotions and decision making: five steps to improve your process. Retrieved July 8, 2020 from https://blogs.cfainstitute.org/investor/

31. Remenova, K., \& Jankelova, N. (2019). How successfully can decision-making style predict the orientation toward well- or ill-structured decision-making problems. Journal of Competitiveness, 11 (1), 99-115. https://doi.org/10.7441/joc.2019.01.07

32. Ruys, K. I., \& Aarts, H. (2010). When competition merges people's behavior: Interdependency activates shared action representations. Journal of Experimental Social Psychology, 46, 1130-1133. https://doi.org/10.1016/j.jesp.2010.05.016

33. Sajid, M. \& Li, M. C. (2019). The role of cognitive reflection in decision making: Evidence from Pakistani managers. Judgment and decision making, 14 (5), 591-604.

34. Shotton, R. (2018). The Choice Factory: 25 behavioural biases that influence what we buy. London: Harriman House.

35. Statman, M., Fisher, K. L., \& Anginer, D. (2008). Affect in a Behavioral Asset-Pricing Model. Financial Analysts Journal, 64 (2), 20-29. https://doi.org/10.2469/faj.v64.n2.8

36. Stojanovic, A., Milosevic, I., Arsic, S., Urosevic, S., \& Mihajlovic, I. (2020). Corporate social responsibility as a determinant of employee loyalty and business performance. Journal of Competitiveness, 12 (2), 149-166. https://doi.org/10.7441/joc.2020.02.09

37. Sun, J., Wu, T. \& Chen, B. (2020). Fear of virus or of competitors? The decision rationales of financial managers under COVID-19. Frontiers in Psychology, 11, 556139. https://doi. org/10.3389/fpsyg.2020.556139

38. Tabesh, P., \& Vera, D. M. (2020). Top managers improvisational decision-making in crises: a paradox perspective. Management Decision, 58 (10), 2235-2256. https://doi.org/10.1108/MD-082020-1060

39. Thaler, R. H. (2015). Misbehaving: The Making of Behavioral Economics. New York: W. W. Norton \& Company 
40. Tversky, A., \& Kahneman, D. (1981). The framing of decisions and the psychology of choice. Science, 211 (4481), 453-458. https://doi.org/10.1126/science.7455683

41. Valaskova, K., Bartosova, V., \& Kubala, P. (2019). Behavioural aspects of the financial decision-making. Organizacija, 52 (1), 22-31. https://doi.org/10.2478/orga-2019-0003

42. Van Horne, J. C., \& Wachowicz, J. M. (2008). Fundamentals of Financial Management. London: Pearson Education Limited.

43. Ziolkowska, B. (2020). Managers` decisions and strategic actions of enterprises in Poland in the face of digital transformation. Ekonomia I Prawo-Economics and Law, 19 (4), 816-824. http:// dx.doi.org/10.12775/EiP.2020.053

\section{Contact information}

prof. Ing. Mariana Sedliacikova, PhD.

Technical University in Zvolen

Faculty of Wood Sciences and Technology

Department of Economics, Management and Business

Slovakia

E-mail: sedliacikova@turvo.sk

ORCID: 0000-0002-4460-2818

Ing. Maria Moresova, PhD. et PhD.

Technical University in Zvolen

Faculty of Wood Sciences and Technology

Department of Economics, Management and Business

Slovakia

E-mail:maria.moresova@tuzvo.sk

ORCID:0000-0001-6815-0724

Ing. Patrik Alac, PhD.

Technical University in Zvolen

Faculty of Wood Sciences and Technology

Department of Economics, Management and Business

Slovakia

E-mail:alac@tuqvo.sk

ORCID: 0000-0003-1804-0396

doc. Ing. Josef Drabek, CSc.

Technical University in Zvolen

Faculty of Wood Sciences and Technology

Department of Economics, Management and Business

Slovakia

E-mail:josef.drabek@tuqvo.sk

ORCID: 0000-0001-6855-6919 